\title{
Metal Work
}

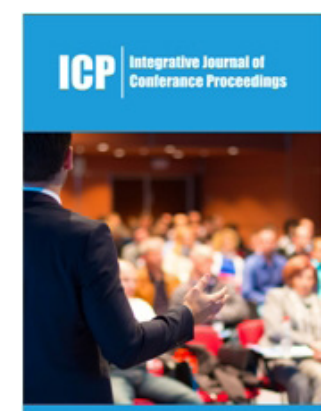

*Corresponding author: Catherine Anne Mathias, Master of Science, Department of Earth Science, Canada

Submission: 侮 May 16, 2019

Published: 紫May 21, 2019

Volume 1 - Issue 2

How to cite this article: Catherine A M. Metal Work. Int J Conf Proc.1(2). ICP.000510.2019.

Copyright@ Catherine Anne Mathias, This article is distributed under the terms of the Creative Commons Attribution 4.0 International License, which permits unrestricted use and redistribution provided that the original author and source are credited.

\author{
Catherine Anne Mathias* \\ Department of Earth Science, Canada
}

\section{Opinion}

As a geologist (MSc) looking at the worlds rapidly growing need not only for petroleum but also metals, one wonders if we will continue to meet these requirements; probably not. This is in part why we continue to have conflicts in the Middle East which tends to impact cultural heritage with both the trafficking of artifacts and the demolition of cultural sites. That said as an Art historian and conservator (PhD) looking at Medieval metalwork from this area and South America I have found our ingenuity to adapt to new materials is quite good. Now as a seasoned researcher to Columbia I have gained a new appreciation for what would have been challenging mining activities for a period spanning from 300 A.D. to 1600 A.D. However, the raw materials made their way to the metal workers shop and the products that survive today are spectacular. The same holds for the metalwork of Mosul Iraq and Kabul Afghanistan. The other fact that I find fascinating is the similarity in technique for areas which did not see trade until recently and that is only speculative and in the drug trafficking areas.

Another area of interest is the chemical composition of the materials used in the metalwork projects. By about 1400 A.D. this material could be sourced anywhere on the globe. To positively establish sources the application of stable isotope geochemistry will likely be required. All metals will have some sort of isotopic signature in their corrosion layer and the gemstones will have even more information in their inclusions which can be extracted by laser ablation.

The degree of manual dexterity required to create the metalwork examples included here and those associated in similar collections is extremely high. As one researcher who has garnered this knowledge from working in beautiful vistas such as Red Bay Labrador to warzones such as Afghanistan and Cartel held zones such as Columbia; if only we appreciated each other at the same level as the material culture we produce peace could be achieved. That said any student of archaeology should make a trip into both Afghanistan and Columbia, the latter is fairly safe at this point. As a tourist destination for those retired, I suggest going to both but if a little squeamish, because one never knows what one will see, try Doha Qatar and view objects at both the National Museum and the Museum of Islamic Art (Figures 1-15).

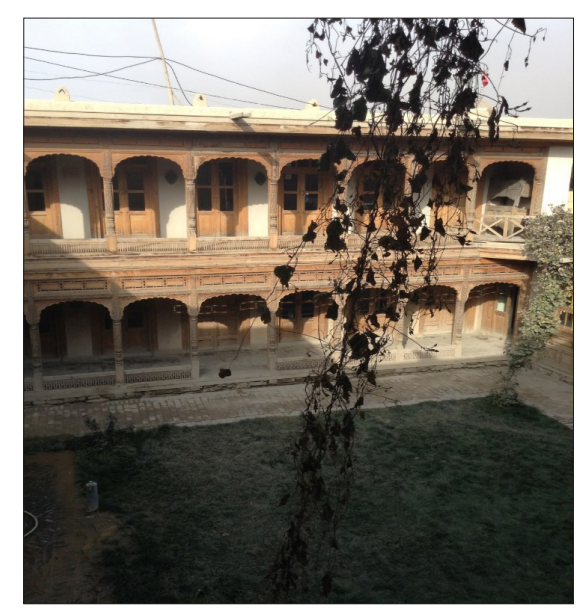

Figure 1: Turquoise mountain jewelry shop; one of the few remaining heritage buildings apart from 12 th century wall which surrounds the old city of Kabul. 


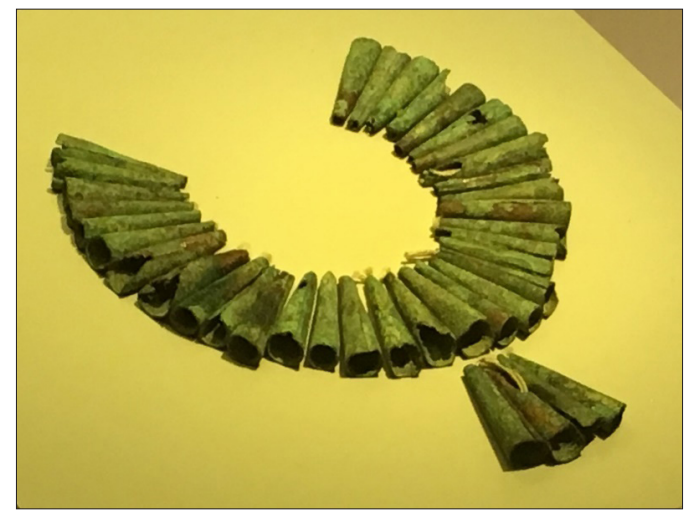

Figure 2: Copper objects at the Gold Museum, Bogota, Columbia, author remembers similar tubes from a aboriginal site at Saddle Island, Red Bay, Labrador; unfortunately the artifacts can no longer be found at the Rooms Provincial Museum, Newfoundland.

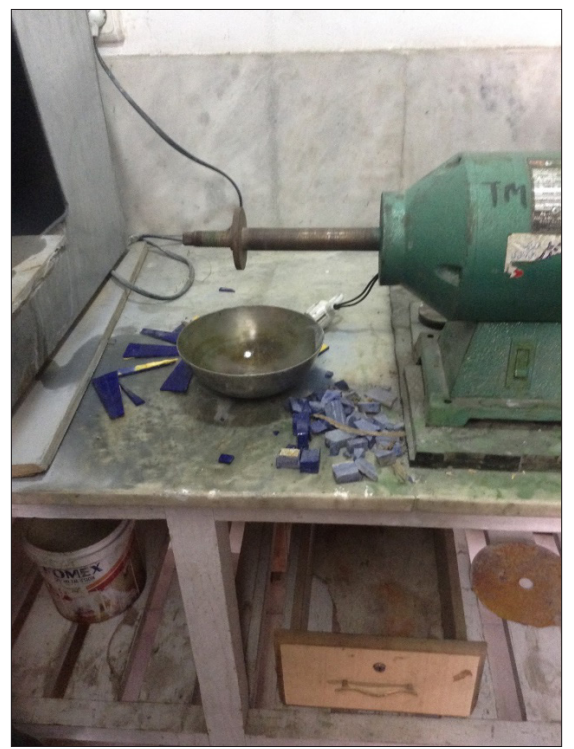

Figure 3: Metalworking area in tourqoise mountain.

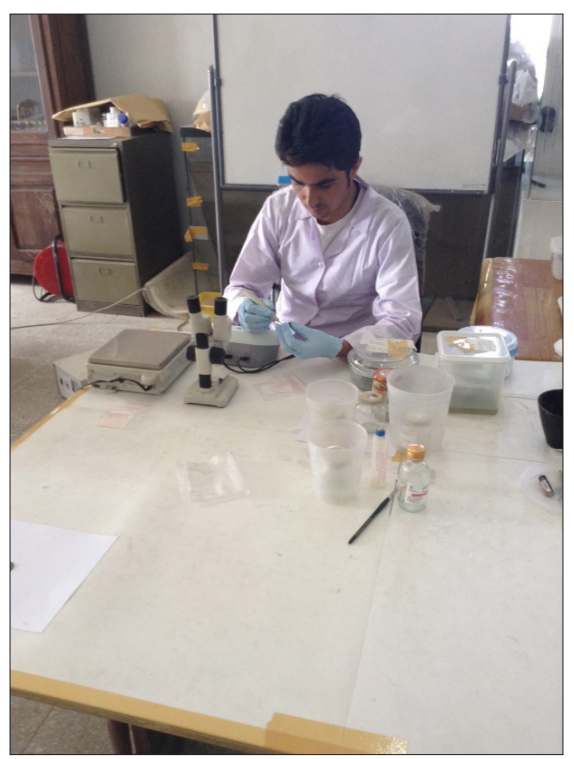

Figure 4: Afghan conservator working on coins at the national museum of Afghanistan. 


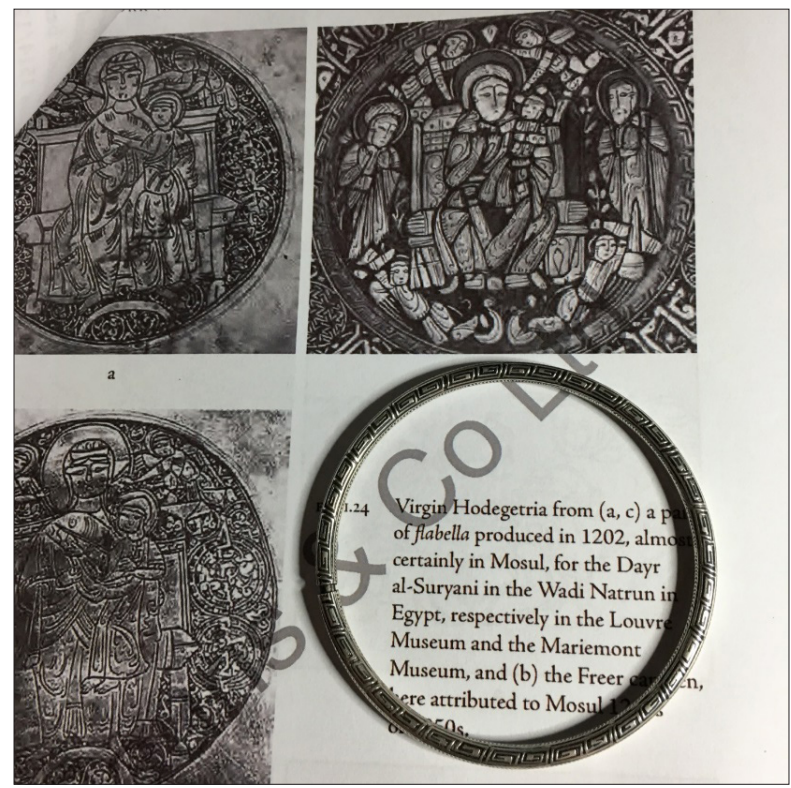

Figure 5: Example of old 13th century design on modern jewelry pieces.

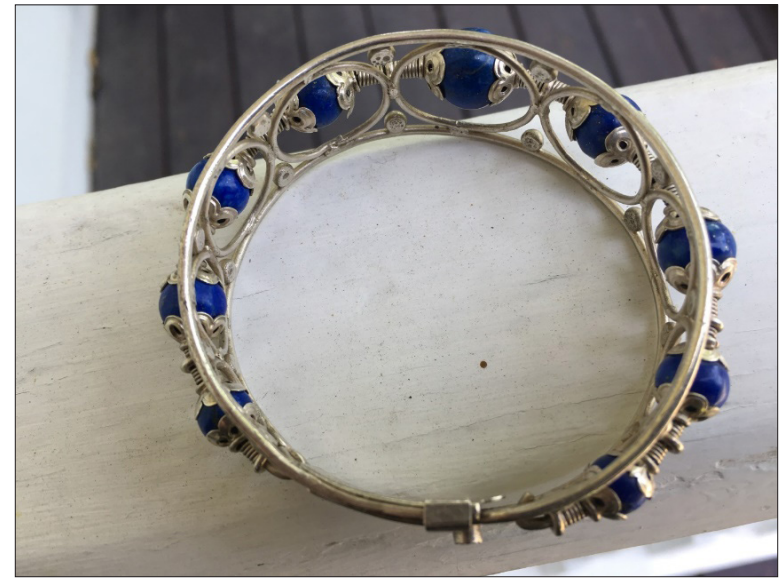

Figure 6: Jewelry piece made by the above afghan conservator for the author when she was working at the national museum of Afghanistan.

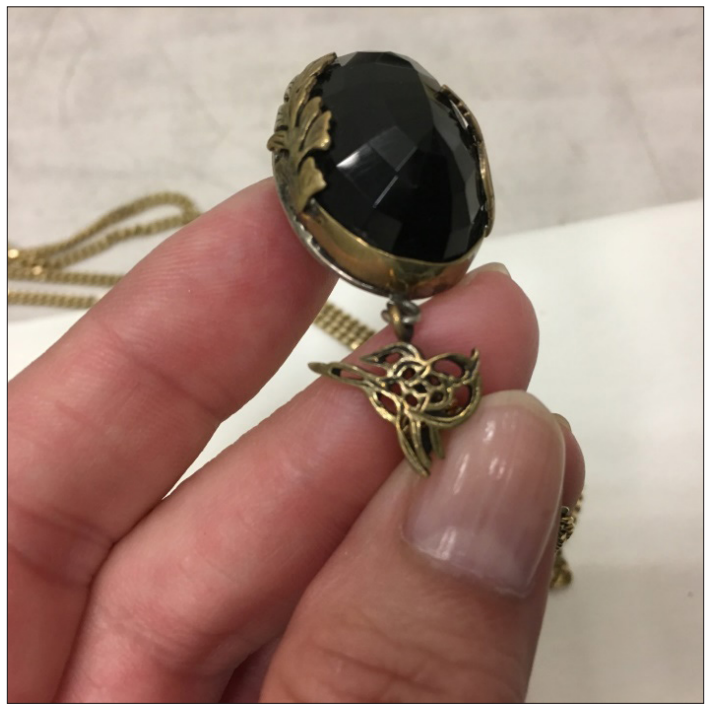

Figure 7: Example of new jewelry following 14th century design elements. 


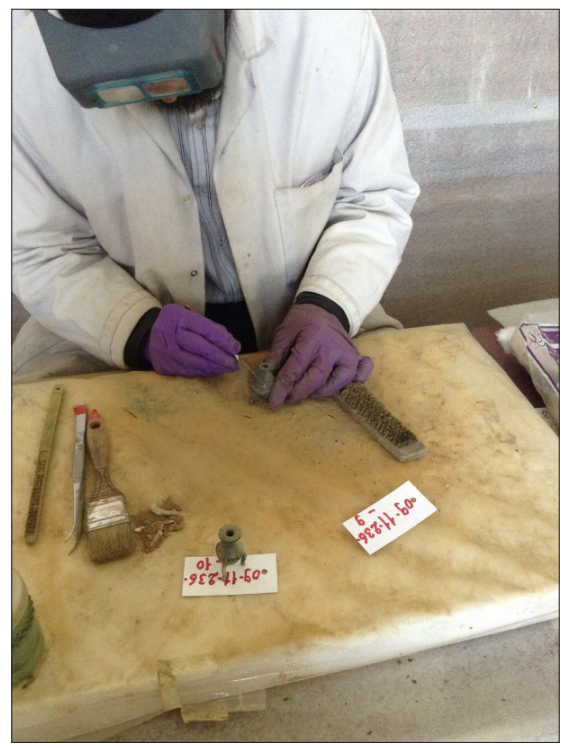

Figure 8: Afghan conservator working with medieval metalwork at the national museum of Afghanistan.

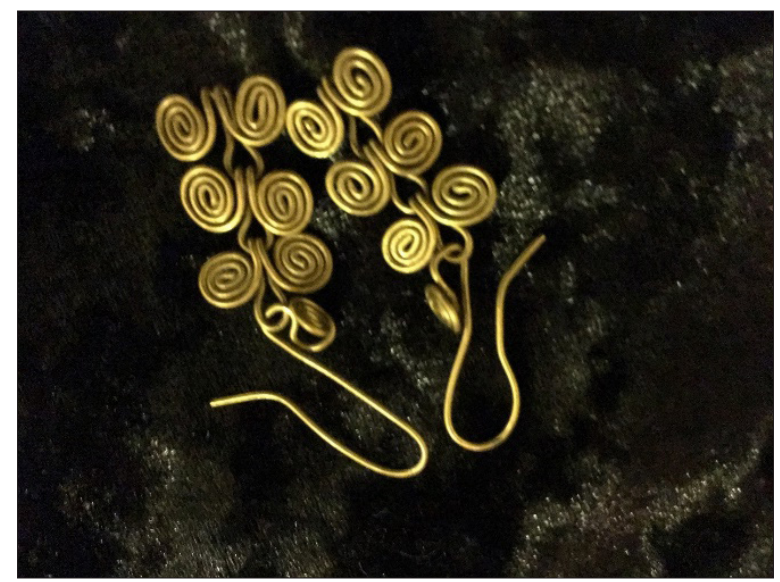

Figure 9: Example of jewelry made by street vendor in bogota Columbia.

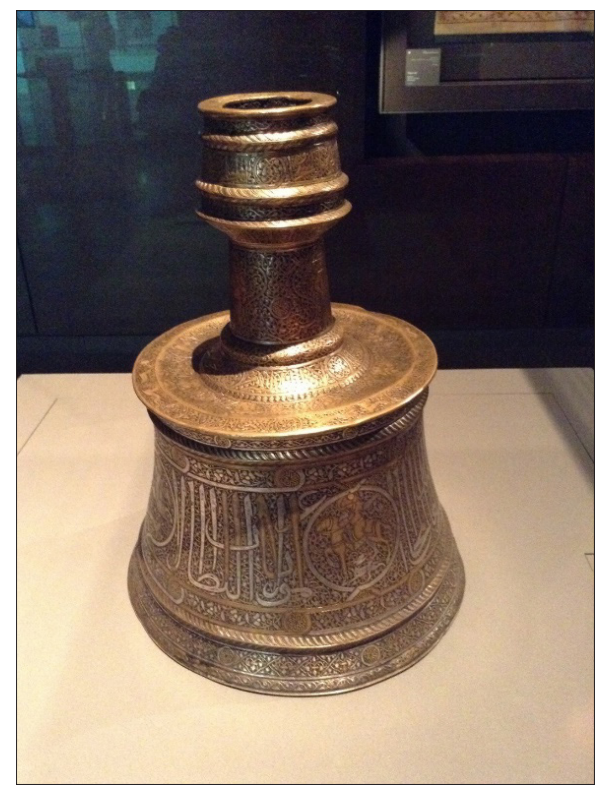

Figure 10: Candle stick from the collection of the museum of islamic art, Doha, Qatar. 


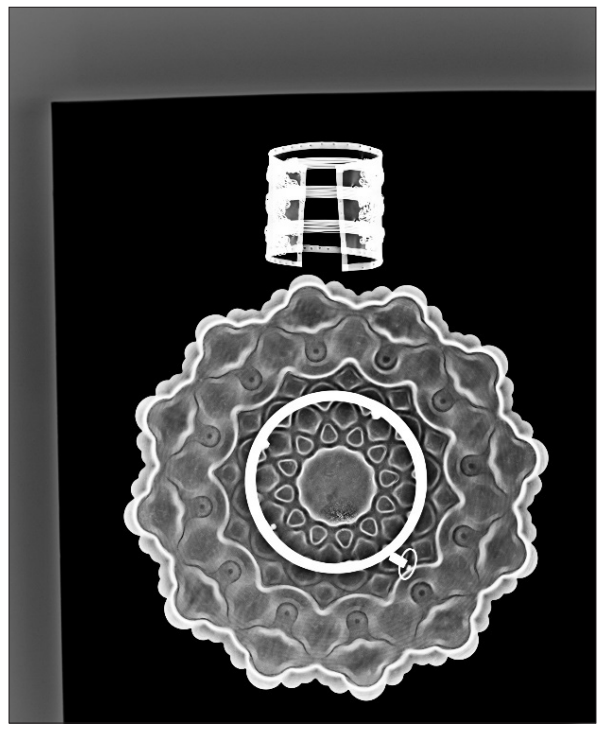

Figure 11: X-radiograph of bracelet from columbia and plate from Iran; image courtesy of Dr. C. Mathias, W. Krawsowski, Dr. James Watt and S. Mathias.

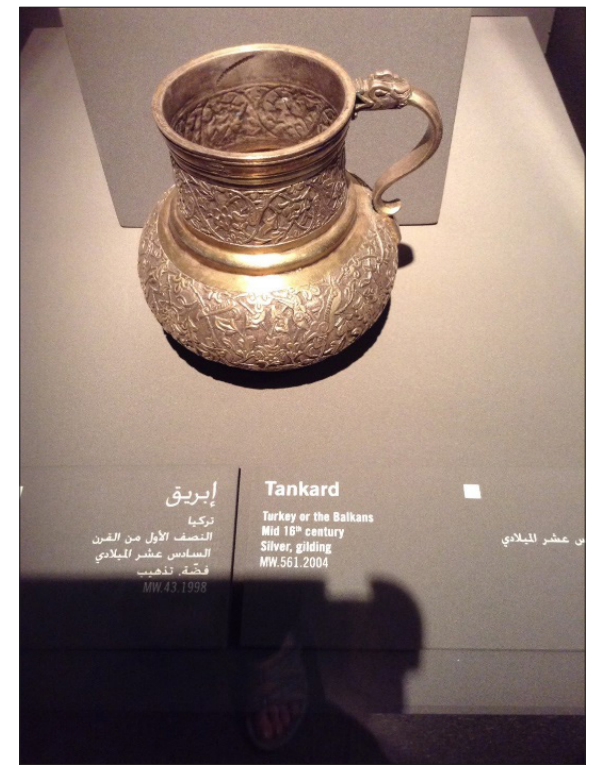

Figure 12: Tankard from the collection of the museum of Islamic art, Doha, Qatar.

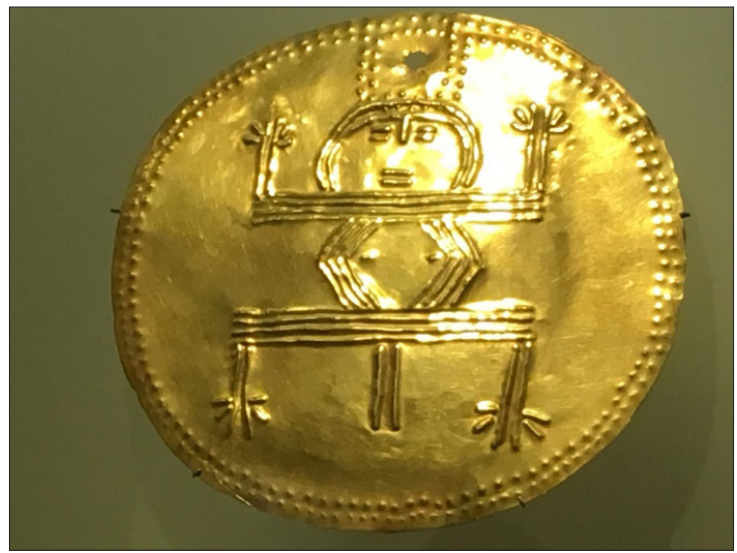

Figure 13: Metalwork from the gold museum, Bogota, Columbia. 


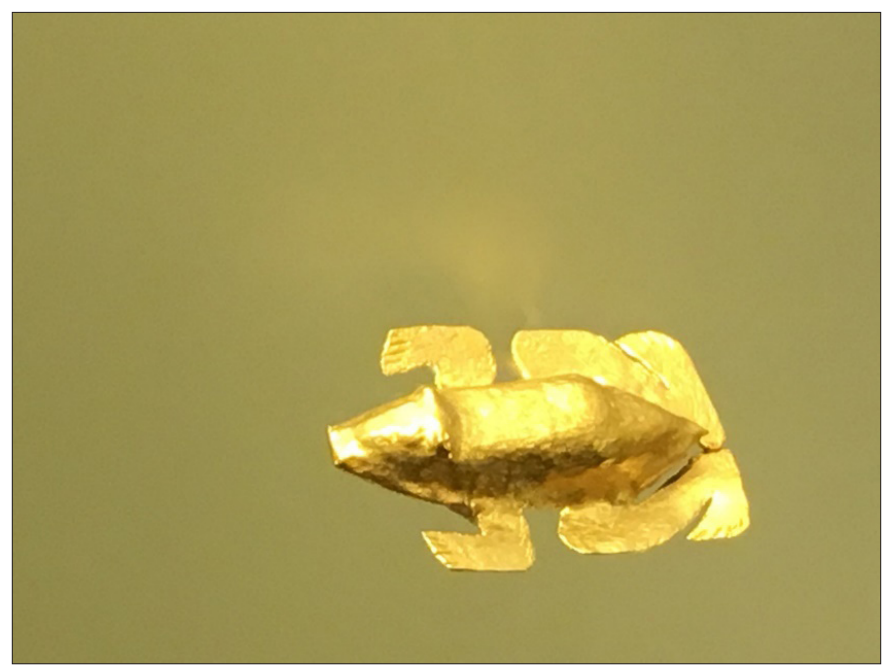

Figure 14: Metalwork from the gold museum, Bogota, Columbia.

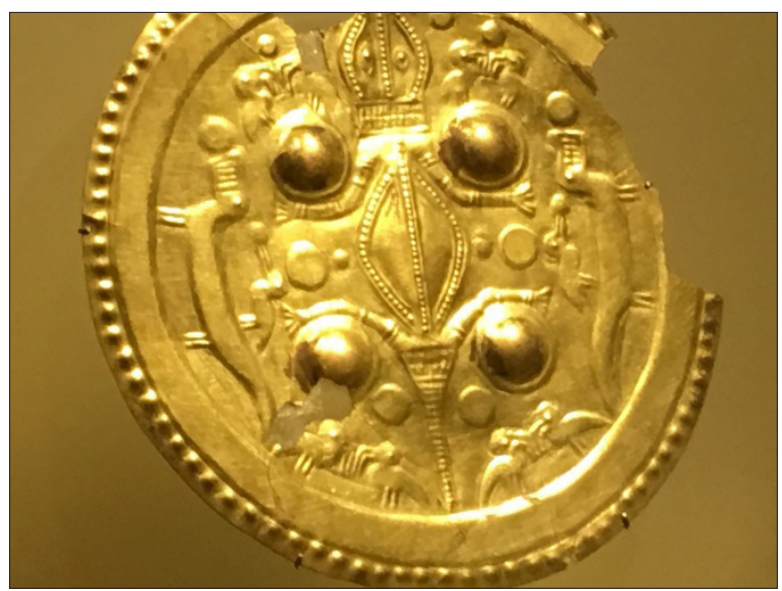

Figure 15: Metalwork from gold museum, Bogota, Columbia.

For possible submissions Click below: 